\title{
Thiersch wiring as a temporary procedure in a haemodynamically unstable patient with an incarcerated rectal procidentia
}

\author{
Ravikiran Naalla, ${ }^{1}$ Raghunath Prabhu, ${ }^{2}$ Rajgopal Shenoy, \\ Inge Gerdina Joanna Hendriks ${ }^{3}$
}

${ }^{1}$ Department of General Surgery, Kasturba Medical College, Manipal, Karnataka, India

${ }^{2}$ Department of Surgery, Kasturba Medical College, Manipal, Karnataka, India ${ }^{3}$ Maastricht University, Maastricht, The Netherlands

\section{Correspondence to} Dr Ravikiran Naalla, ravi_2488@yahoo.co.in

Accepted 6 June 2014
CrossMark

To cite: Naalla $R$, Prabhu $R$, Shenoy $\mathrm{R}$, et al. BMJ Case Rep Published online:

[please include Day Month Year] doi:10.1136/bcr-2014204822

\section{DESCRIPTION}

A 35-year-old man presented with complete rectal prolapse which was irreducible for 2 days. He was diagnosed to have a rectal prolapse 6 years ago when he noticed a mass protruding through the anus. Initially, the mass protruded from the anus only after a bowel movement and retracted spontaneously. As the disease progressed, the mass protruded more often, especially with straining and sneezing or coughing and he had to manually replace it. The patient never came for follow-up in 6 years. He does not have bleeding per rectum or pain in the abdomen. He does not have faecal incontinence. On examination the patient was anxious and dehydrated. His pulse rate was 100/ min and his blood pressure was 90/60 mm Hg. He had a full thickness rectal procidentia with mucosal congestion and oedema with whitish flakes over the rectal mucosa (figure 1). There was no evidence of ulceration or bleeding. Routine blood investigations revealed iron-deficient anaemia (haemoglobin: $9 \mathrm{~g}$ $\%$ ) and elevated blood urea nitrogen (urea: $40 \mathrm{mg}$ $\%)$. The patient was anxious and the mass could not be reduced at the bedside; hence he was shifted to the operation theatre where he was sedated, $2 \%$ lignocaine jelly was applied over the rectum and the mass was reduced with gradual pressure.

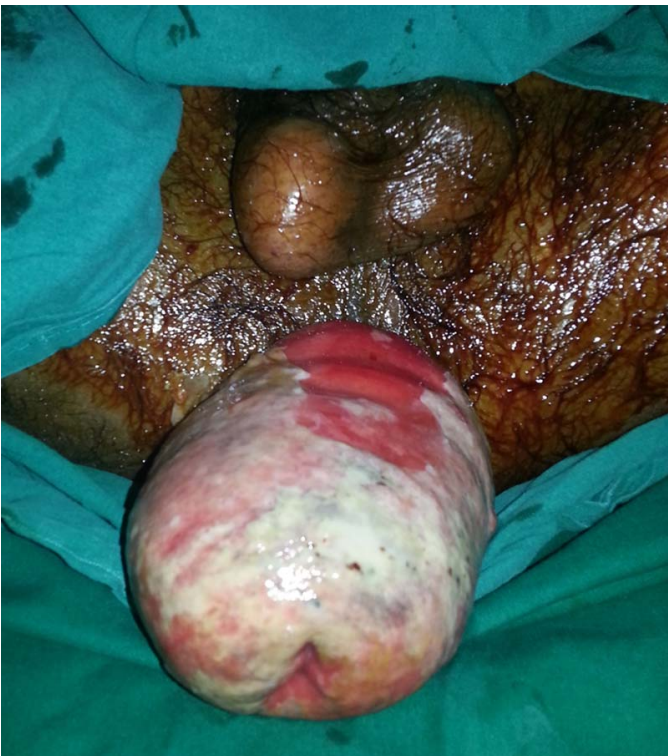

Figure 1 Full thickness rectal procidentia $(12 \times 6 \mathrm{~cm})$ with mucosal congestion and oedema associated with whitish flakes over the mucosa.
Decreased anal sphincter tone was noted. Two per cent lignocaine was infiltrated around the anal orifice and 1'0 prolene suture was placed around the anal orifice in subcutaneous plane and tightened over a finger (as a purse string suture; figure 2) to prevent excessive narrowing of the anal orifice. The rectal procidentia was completely reduced (figure 3). Postprocedure there was no rectal prolapse after performing a Valsalva manoeuvre. The patient was resuscitated meanwhile and planned for elective abdominal rectopexy on a later date.

Rectal prolapse is a condition in which the entire layer of the rectal wall protrudes through the anal canal. Haemorrhage occurs frequently in cases in which the prolapsed rectum is left unreduced. If severe haemorrhage or strangulation is detected, emergency treatments should be administered. ${ }^{1}$

Thiersch procedure (anal encirclement) is performed frequently in patients with old age or high risks with rectal prolapse. It is a simple procedure using a suture or prosthesis that narrows the anus. When it was reported for the first time by

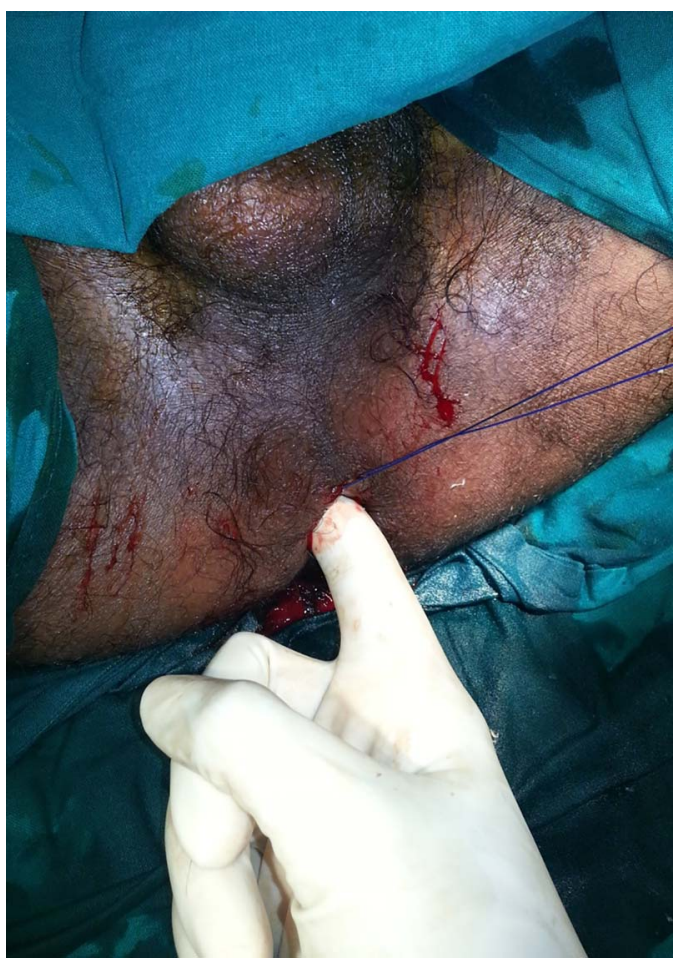

Figure 2 1-0 prolene placed around the anal orifice in the subcutaneous plane and then tightened over a finger (as a purse string suture). 


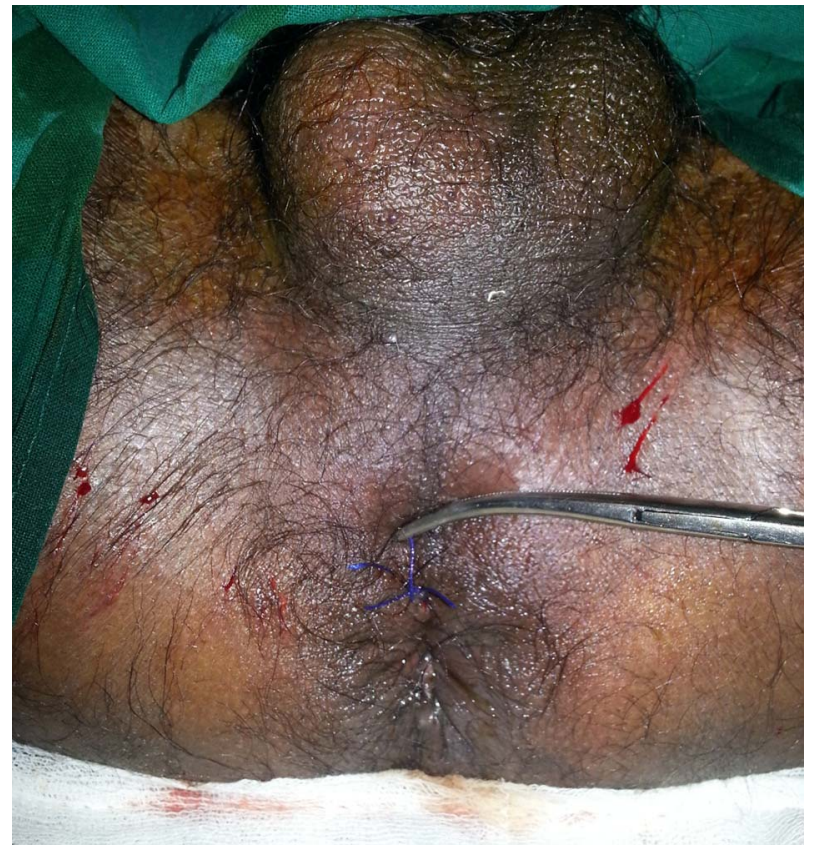

Figure 3 Completely reduced rectal procidentia.

Thiersch $^{2}$ a silver wire was used as a prosthesis. Presently, because of ulcers and other complications, instead of wires, sutures and nylon, dacron, silastic, teflon and silicon rubber materials are used. ${ }^{1}$ Our patient was haemodynamically unstable, hence the patient would not tolerate a major perineal or abdominal procedure in the acute setting, so we performed a minor Thiersch procedure which would prevent strangulation and/or bleeding complications of an incarcerated rectal prolapse. Moreover, we could buy some time for planning a better and permanent procedure. As the patient was young we would prefer a posterior prosthetic rectopexy through an abdominal approach once he is stabilised and the rectal oedema subsides, as it gives better results than the perineal procedures. ${ }^{1}$

\section{Learning points}

- Thiersch procedure is a useful modality in the treatment of high-risk patients with rectal prolapse; it can also be used as a temporary treatment till definitive treatment is planned.

- Haemorrhage occurs frequently in cases in which the prolapsed rectum is left unreduced.

- Abdominal procedures have better outcomes when compared with perineal procedures for the treatment of rectal prolapse.

Contributors RN participated in writing and publishing the article and RP, IGJH, RS participated in proofreading.

\section{Competing interests None.}

\section{Patient consent Obtained.}

Provenance and peer review Not commissioned; externally peer reviewed.

\section{REFERENCES}

1 Shin EJ. Surgical treatment of rectal prolapse. J Korean Soc Coloproctol 2011;27:5-12.

2 Thiersch C. Carl Thiersch 1822-1895. Concerning prolapse of the rectum with special emphasis on the operation by Thiersch. Dis Colon Rectum 1988;31:154-5.

Copyright 2014 BMJ Publishing Group. All rights reserved. For permission to reuse any of this content visit http://group.bmj.com/group/rights-licensing/permissions.

BMJ Case Report Fellows may re-use this article for personal use and teaching without any further permission.

Become a Fellow of BMJ Case Reports today and you can:

- Submit as many cases as you like

- Enjoy fast sympathetic peer review and rapid publication of accepted articles

- Access all the published articles

- Re-use any of the published material for personal use and teaching without further permission

For information on Institutional Fellowships contact consortiasales@bmjgroup.com

Visit casereports.bmj.com for more articles like this and to become a Fellow 